\title{
Design of computer-assisted education programs for optics and photonics: implications of educational technology research
}

\section{Stephen Pompea}

Stephen M. Pompea, "Design of computer-assisted education programs for optics and photonics: implications of educational technology research," Proc. SPIE 4588, Seventh International Conference on Education and Training in Optics and Photonics, (28 May 2002); doi: 10.1117/12.468734

SPIE Event: Education and Training in Optics and Photonics 2001, 2001, Singapore, Singapore 


\title{
Design of Computer-Assisted Education Programs for Optics and Photonics: Implications of Educational Technology Research
}

\author{
Stephen M. Pompea ${ }^{\mathrm{a}}$ \\ ${ }^{\mathrm{a} P o m p e a} \&$ Associates, 1321 East Tenth Street, Tucson AZ 85719-5808 USA ${ }^{1}$
}

\begin{abstract}
The design of computer-assisted educational materials and programs is a specialty of science education and relies heavily upon the results of science education and educational technology research. This paper explores the implications of this research for successful computer-assisted instruction. Two areas are examined: (1.) Simulations and problembased learning environments (2.) The basis for the evaluation of distance learning course software. Examples will be given using a project developed by the NASA Classroom of the Future, at the Center for Educational Technologies at Wheeling Jesuit University. There are a number of optics-related computer simulations in CD-ROM based programs such as the award winning Astronomy Village: Investigating the Universe. Most educational designers can identify the characteristics of a good educational simulation. The design of an entire course delivered over the Internet requires high quality software that can maximize not only course material delivery but the conversation and information exchange that must take place as well. A model approach for an entire course using such software will be presented. Particular care will be given to how one evaluates the course software.
\end{abstract}

Keywords: optics education, computer-assisted instruction, multimedia, instructional materials

\section{INTRODUCTION}

"I believe that the motion picture is destined to revolutionize our educational system and that in a few years it will supplant largely, if not entirely, the use of textbooks."

Thomas Edison, 1922

Every generation of technologists for the last 100 years have viewed technology as an important vehicle to improving or supplanting the current educational system. However, the educational system has proven remarkably stable as technology is integrated into the current system rather than supplanting it. Teachers and classes still operate much the same even with new technology. Teachers are still considered the key to a wider use of technology. As technology has evolved, new learning paradigms are possible, depending on the strengths of the technology and its flexibility. The Internet has proven to be a surprisingly powerful and flexible technology. New course preparation and delivery software represents a considerable advance in flexibility and utility for web-based courses and training. The optics and photonics industry increasingly relies on distance learning over the Internet for delivery of its course and educational materials.

The most desirable attributes of distance learning technology are power, ease of use, and flexibility. At the university level, there is an increased emphasis on providing on-line courses. Course delivery software provides a flexible vehicle for conducting courses of widely varying content and educational philosophy. This software must provide support for traditional lecture-based courses as well as discussion-based seminars. It also must have the power and flexibility to support group projects and group presentations. It should also support a number of authentic and alternative assessments such as portfolio-based assessments. This paper examines some of the ways in which computer-assisted instruction can be used in scientific and technology education, and argues for using technology for its interactive capabilities rather than for its ability to deliver content.

\footnotetext{
${ }^{1}$ Science Education Consultant, Also Education Co-Chair, Arizona Optics Industry Association, Adjunct Faculty, University of Arizona, Telephone 520.792.2366 Email spompea@pompea-associates.com
} 


\section{RESEARCH ON TECHNOLOGY IN THE CLASSROOM}

Effective instruction using computer technology shares many of the same attributes as effective laboratory instruction. Both have the potential to be highly interactive and to reinforce an understanding of science process. Research in science laboratory instruction (Lazarowitz \& Tamir, 1994) shows how lab sessions can have several advantages over more conventional presentations and can promote gains in student learning. Among them are: ${ }^{1}$

- The investigations will aid students' development of inquiry skills and give them an appreciation of the scientific enterprise and the interplay between technology and science.

- The investigative approach promotes the development of cognitive skills such as problem solving analysis, generalizing, critical thinking, applying, synthesizing, evaluating, and decision-making.

- Investigational, organizational, and communicative skills are used regularly and developed.

- Investigations provide a concrete experience and opportunity to confront student misconceptions (or alternative conceptions, as the case may be).

- The data manipulation and analysis activities provide an understanding of the continuity of the scientific process.

- The concrete props and opportunities for manipulation of physical objects are valuable for students with kinesthetic learning styles.

- The cooperative learning environment promotes an examination of the data from different perspectives and provides strong motivation for students to stay on task.

- The investigational environment provides ample opportunity for building and communicating values concerning the nature of science.

Computer-assisted instruction in optics and photonics can have many of the attributes of lab instruction. It can provide an enriched experience that encourages inquiry. If the instruction mainly delivers content, then perhaps a book or videotape would be preferable to Internet delivery. One effective form of computer-assisted instruction is based on problem-based learning, in which problem-solving skills are encouraged, often through the use of more complex vague or ill-structured problems. Students must define the problem and work through a solution. These problem-based learning educational experiences are often in the context of simulations and simulation environments. In these environments the student is responsible for solving a problem. These kind of educational environments are inherently more interesting than simple drill-based environments.

\section{SIMULATIONS AND SIMULATION ENVIRONMENTS}

There is a wide body of research on computer-assisted instruction and simulations. The research suggests that the use of simulations can lead to a deeper understanding of the information. ${ }^{2}$ Simulations are particularly effective when it is impossible to experiment with the real system and to study the behavior of a system over time. ${ }^{3}$ For example, the behavior of light as it passes through the atmosphere is the subject of much modeling and simulation. The use of adaptive optics in astronomy and defense applications is of considerable interest. Students studying this subject can pursue a deeper understanding of atmospheric optics using simulations. These smaller simulations can be embedded in a larger simulation environment, that of a scientist on a research team pursuing an understanding of problem such as atmospheric seeing.

One such piece of "simulation" software is the Astronomy Village: Investigation the Universe multimedia program, developed by the NASA Classroom of the Future Program at Wheeling Jesuit University ${ }^{4}$. It is a multimedia program designed as a supplement to 9th grade (14 year old students) earth science or physical science curriculum. The basis of the software is that student research teams go to the "Astronomy Village" to work on an astronomical investigation for about three weeks. One of the investigations is on selecting an observatory site, and involves looking at the properties of atmospheric seeing at different locations. At the Astronomy Village students meet the leaders of the research teams and choose an investigation to pursue, much like a summer internship program. Then the students become seriously involved in the research process. They actively construct inferences, relations, comparisons, questions, and mental models. They solve problems and analyze images using image processing. They even face the press in a press conference after presenting their results. The Astronomy Village multimedia program can be used as a culminating 
activity to an astronomy unit or as a general resource for teachers and students. Although not designed to teach optics, the optics modeling is based on the author's experience with atmospheric seeing models used in designing adaptive optics systems.

The Astronomy Village multimedia program is designed to emphasize the process of science as much as content. In this CD-ROM-based multimedia program, student teams can pursue one of ten research investigations. In each investigation they are guided by a mentor, receive e-mail, hear a lecture in the Village auditorium, and make observations using ground or spacebased telescopes in a virtual observatory. The students also process

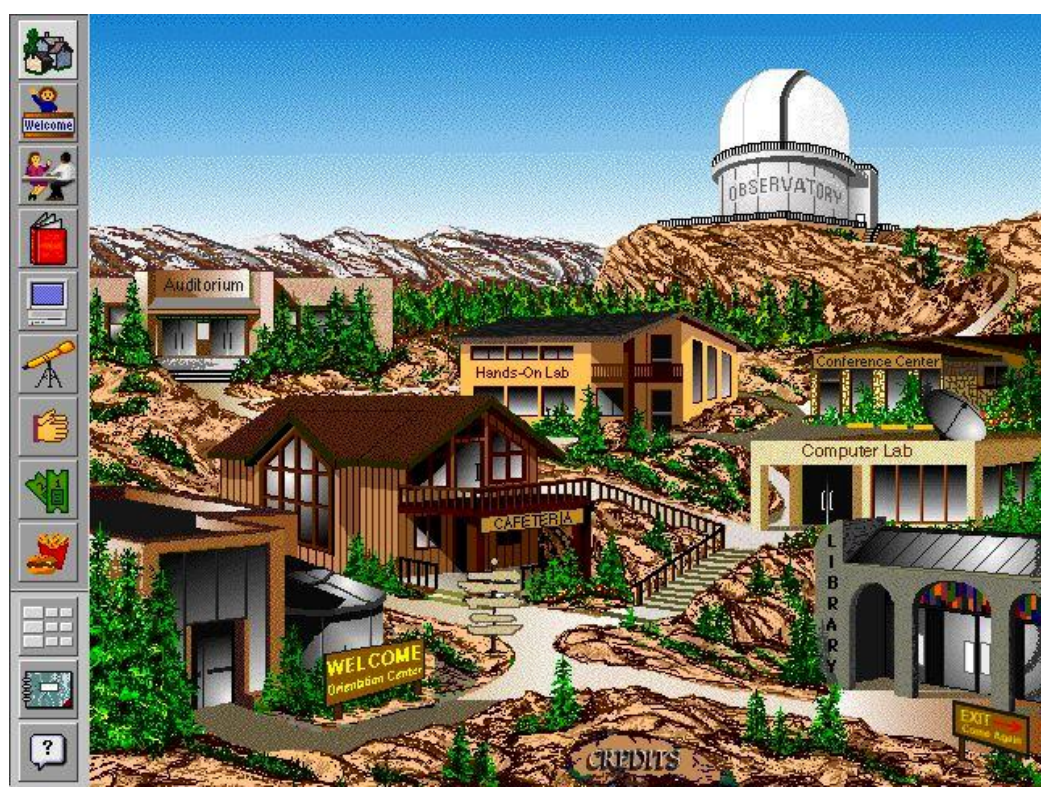
data using the NIH Image image processing program. They keep a detailed logbook of their research activities and can run simulations on stellar evolution as well as manipulate 3-D astronomy visualization tools. At the end, they present their research results to their classmates and answer questions about their results at a press conference. The Astronomy Village builds upon previous work in the use of image processing for education (Pompea $\left.{ }^{5}, 1994\right)$, teaching techniques in astronomy (Pompea $\left.{ }^{6}, 2000\right)$ current research in astronomy (Pompea $\left.{ }^{7}, 1995\right)$, and developments in optics education (Pompea and Nofziger $\left.{ }^{8}, 1995\right)$.

Like most scientists, the students work in cooperative research teams. The student teams have three members, with each student specializing in certain areas, such as image processing or using the telescope. The use of cooperative learning has proven to be an effective learning tool. Students generally need some training in the general scientific/engineering process. Training in science process might be the most important thing they get from such a course. Our assumptions about that process are:

(a) Science is a contact sport. Students learn about science by actively constructing and discussing inferences, relations, comparisons, questions, and mental models.

(b) Science is a social activity and is not an isolated activity.

(c) Students should learn science the way that scientist do science.

(d) Students need real-world problem solving skills. If we expect students to solve problems, they must be given practice and training in problem solving.

(e) Higher order thinking and creativity should be encouraged.

In their Astronomy Village work, students are working on real problems rather than simple problems with easily known answers. The development team felt that this form of problem-based learning was of greater value than simpler problems.

\section{VALUE OF PROBLEM-BASED LEARNING}

Educational research shows that problem solving is a complex skill and differs depending on the type of problem that is posed. Well-structured problems are well-defined, and often have a single correct answer. Simple equations or unit conversions between metric and English units would fall into this category. Many real-word problems are ill-structured in nature. These problems are less well-defined, are more difficult to solve, and require a different set of skills. Researchers have shown that problem solving ability relies on a set of related skills. These skills include conceptual understanding in an area, general metacognitive abilities, and attitudes towards science (Hong ${ }^{9}$, 1998). In her study of 
the Astronomy Village multimedia software, Hong showed that there is a significant dichotomy in the skills needed for well-structured versus ill-structured problem solving. In general, ill-structured problems have more than one valid solution and can be solved in more than one way (Simon, ${ }^{10}$ 1973). Most of the problems in the Astronomy Village are ill-structured. Many research studies demonstrate the value of inquiry-based instructional strategies such as what was used in the Astronomy Village. These strategies produce significantly greater problem solving skills and science achievement than more conventional instructional strategies (see for example Anderson, et al. ${ }^{11}$, 1975; Tobin $^{12}$, 1986; Cavin \& Lagowski ${ }^{13}$, 1978). The Astronomy Village program is delivered on a CD-ROM. Many photonics courses are now being delivered over the Internet, the latest manifestation in the evolution of communications technology.

\section{ADVANCES IN EDUCATIONAL TECHNOLOGY}

Educational technology has advanced with the general evolution of communications technology. Each new technology has developed its constituency and promoters. Each technology has the possibility of capturing something new or of presenting something new to the students. These tools allow new forms of educational communication or reflection to take place. In some cases the technology allows the exploration of phenomena that normally would be hard to visualize. The table below describes some of the advances that have taken place over the last 100 years.

Course delivery software builds on the Internet and WWW and allows information to be presented in a variety of communications formats. It is flexible in that it can be used with slower modems or with faster cable modems or DSL lines. In the latter case, streaming video and audio can be used for greater authenticity and contact with instructors, or with other class members.

\begin{tabular}{|l|l|l|l|}
\hline Lantern Slides & Radios, Recordings & Filmstrips, Movies & Instructional Television \\
\hline Language Labs & Planetaria & $\begin{array}{l}\text { Microcomputer-Based } \\
\text { Labs }\end{array}$ & Calculators \\
\hline $\begin{array}{l}\text { Computers with CD- } \\
\text { ROMS }\end{array}$ & $\begin{array}{l}\text { Image Processing } \\
\text { Programs }\end{array}$ & Simulation Programs & $\begin{array}{l}\text { Virtual reality and remote } \\
\text { presence }\end{array}$ \\
\hline Internet and WWW & Java Applets & Virtual Machines & $\begin{array}{l}\text { High Bandwith } \\
\text { Telecommunications }\end{array}$ \\
\hline
\end{tabular}

\section{FORMS OF DISTANCE EDUCATION}

Distance education as a field has expanded and advanced with changes in technology. Some of the stages in the evolution of distance education are:

\section{Distant Past}

Distance education once had a heavy reliance on print material delivered by the post office. The student worked independently to learn the material and there was little or no group process involved. The delivery of the course paid little attention to how individual students learn and there was no adaptation possible for individual learning styles. Tests were administered by mail as well, and feedback on exam performance was slow. Often a textbook was used to provide background material. Questions about the course material could be relayed by letter or by telephone. Some distance learning programs relied upon tutors at regional learning centers to aid and support students.

\section{Yesterday}

The field of distance education advanced to the use of videotape, satellite broadcasts, and cable TV. Videotape allowed the learner to approach the course material at times of his or her convenience and at a pace that was somewhat selfprescribed. With satellite or cable TV broadcasts of lectures, the student would often attend the lecture at a specified time. In some cases, whole classes of students would meet together at a remote location to view the course lecture. This often occurred in the case of engineering education where a graduate, continuing education course might be offered at a specific company location. The telephone was increasingly used for questions, and could be used in the middle of the lecture to directly address the professor. Often a textbook was used to provide background material. There was a heavy 
reliance on lectures and much of the formal course took place with the remote synchronous involvement of the instructor. These courses had little or no adaptability for individual learning styles.

\section{Today}

Distance education today is often delivered via the Internet with less reliance on textbooks. In many courses there is little or no live presence of instructor. Questions are submitted via email, but instructors and their assistants are often overwhelmed by the number of questions. Some typical questions are answered and posted on the web.

There are significant bandwidth limitations and video and audio streaming is still not widespread in this arena. Exams are given on-line in many cases, though there is a concern about cheating in on-line exams. Some professors require the students to take exams in a proctored situation. Many professors have gone to project-based grades and have put less reliance on closed-book exams. There is some adaptability for individual learning styles in that students can often choose their course activities or projects from a menu list. The other adaptable element in the courses is that students can work at any time of day or night that they wish. In some courses, student progress is monitored on a weekly basis. In other courses the students have to complete a list of items by the end of the semester.

\section{The Future}

Distance learning in the future will have many of today's components augmented to make the courses more desirable. The students of the future will have many courses to choose from and each on-line university will have to convince the consumer-student of the advantages of their particular courses. Distance learning courses will consists of broadcasts of mixed media in high quality formats. The broadcasts might be live lectures or discussions or could have been recorded at an earlier time. The courses might also include synchronous components to build group rapport among students who can schedule a specific time to be together online. The courses will also operate in an asynchronous mode where the class is open 24 hours a day, 7 days a week. On-line exams and the posting of project work will be common. Project work will be done by groups of students as is done at the University of Phoenix in its non-web-based graduate business courses.

The future will see a much greater emphasis on group work. Software to effectively facilitate group work among geographically unrelated learners is essential. Interaction with instructors will become a competitive advantage since asynchronous courses that have little instructor presence will be competing with more intimate courses that have a "social" presence. Ability to interact with an instructor will be important for graduate courses and seminars. Courses must also have significant adaptability for individual learning styles. Courses will be offered in a variety of languages and in a variety of time formats. The traditional semester or quarter time-based courses may give way to competency testing with students receiving credit for achieving a certain amount of learning. Assessment may vary widely depending on the type of course and the desire of the instructor. Some courses will have a traditional multiple choice test, while other course may rely on portfolio assessment or group project results posted on the internet.

Course delivery software provides strong support for broadcast of resources by the instructor. It also provides strong support for broadcast of resources by students. Thus it is ideal for group project work and for presentations by a group to other group. This software allows live lecture broadcasts as well as the storage of lecture slides and other materials for future reference. It allows live question and answer sessions and the ability to preserve these sessions for future reference. Its drag and drop interface allows easy real-time assembling of presentation material in response to class feedback.

Future distance learning programs will have great flexibility in how courses are presented, the balance between synchronous and asynchronous communication, the role of lectures, question periods, group discussions, and group projects, and the form of assessment. 


\section{CLASSIC DISTANCE EDUCATION CHARACTERISTICS AND TYPES}

Distance learning can be divided into four categories. Each category has a different software and hardware support system and is appropriate for different kinds of learning situations.

1. Same Time/Same Place Instruction or face-to-face meetings require support technology in the way of overhead projectors, electronic blackboards, and computer projection equipment. The main software that could be used is software to record group activities or group processes for future reference.

2. Same Time/ Different Place Instruction usually involves meeting through a telecommunications medium where participants can interact. An example of this is two- way teleconferencing. Another example is a non-interactive broadcast to large groups without the possibility of easy feedback or interaction. Television and radio both fall into this latter category.

3. Different Time/ Same Place Instruction is still used in some distance learning situations. Examples of this type of instruction occur at local study centers where students can come in to interact with instructors.

4. Different Time/ Different Place Instruction can be either non-interactive or interactive. The non-interactive approach would involve one-way information transmittal via books, audio, and videocassettes, for example. The interactive approach could be computer-mediated instruction with some contact with the instructor or interaction that takes place only between the learner and the computer.

Most computer-based instruction is Same Time/Same Place Instruction or Different Time/ Different Place Instruction.

The best software can be used in either Same Time/Same Place Instruction or Different Time/ Different Place Instruction, or both without any reconfiguring.

\section{BASIC QUESTIONS ABOUT TECHNOLOGY FOR DISTANCE EDUCATION}

An evaluation of software should be done using questions integral to educational research on distance education. These questions deal with a variety of educational issues such as interaction, learner control, transactional distance, motivation, and the social context of learning.

Good software should be very effective in each of these areas.

Does it Support Different Types of Interaction?

- Learner-instructor?

- Learner-content?

- Learner-learner?

Does it Allow an Appropriate Amount of Independence and Learner Control?

- Reinforce perception from student that their success is a result of their own efforts?

- Allow students to make choices?

- Allow students to develop competence (ability and skill)?

- Allow human and instructional material support when needed?

Software should support different types of interaction, allow a balance of independence and learner control, decrease the perception of transactional distance, and support a social context for the course.

Does it Decrease the Perception of Transactional Distance?

- Increase learner control?

- Increase amount of dialogue? 
Comments: Software should encourage dialogue and information exchange while giving learners a sense of being in charge of course resources. Dialogue can flow in any direction with any special audience that a member wishes to identify. Communication can flow broadly to all course members or into narrow channels or small groups.

Does it Help Create a Social Context, which improves motivation?

- Create a sense of immediacy?

- Create a sense of intimacy?

- Allow for encouragement cues given by teacher?

Comments:Software should have the power to create a sense of immediacy and group identity. Encouragement cues can be delivered via streaming video. Since the software allows individual members to present to each other, a strong social context of equal learners is created.

This social context balances one of the greatest shortcomings of web-based courses. Software needs to assist in creating a community of learners, yet allowing the instructor or an individual to easily broadcast information resources to the whole group.

\section{ISSUES IN CHOOSING COMPUTER-BASED INSTRUCTION TECHNIQUES}

Software should be evaluated using the following questions about on-line course development and the student learning process.

\section{Key Attributes}

- Is the educational outcome of the overall delivery system acceptable?

- Is it cost-effective?

- Does it allow for flexibility in student schedules?

- Is it easy for the learner to acquire and use the necessary technology?

- Are steps taken to avoid students being lost in "hyperspace" (i.e. distracted by hypermedia environments)

\section{Does it Allow Easy Introduction of Resources?}

- Text?

- Images?

- Movies?

- Real-time views of instructor?

- Real-time views of students?

- Sharing of resources among students?

- Asking of questions and informal interaction?

- Archiving of information?

Comments: Text, images, and movies should be easily introduced and archived. Students and the instructors should be able to participate with video streaming using inexpensive web cams. Students should be able to easily share resources and ask questions. There is a desire for informal interaction to be supported in text-based mode or through video/audio streaming.

Does it Support the Student Learning Process?

- Aid learners in helping to select relevant information?

- Help students organize the information into a coherent outline?

- Help students relate the outline to a structure or event they are familiar with?

- Help students select, organize, integrate information?

Comments: The outline of resource material and presented material allows students to quickly organize presented materials. The outline and directory structure of the resources should be in a form familiar to students. Students can easily select and organize information to present to each other, or to themselves. 


\section{Does it Support the Instructor?}

- Easy to use by instructor?

- Adaptable to material already created for course?

- Allow for teacher centered and student centered activities?

- Allow for teacher to be information sources and distributor of knowledge?

- Allow for teacher to be facilitator?

- Give rise to more intelligent forms of teacher-student relationships?

- Is the technology flexible enough to easily switch from the instructional paradigm to the conversational paradigm?

Comments: The interface should be easy for the instructor to use. It should allow the instructor to easily add new material or to adapt an existing course and course resources to the software. The instructor can be an information source and distributor or can be a facilitator since students have the ability to access the course information resources. By allowing the student to teach other students, and by allowing the instructor to monitor student communication and progress, the teacher can learn of the students' areas of difficulty. The technology supports both a top-down instructional paradigm as well as the conversational paradigm essential for seminars and many graduate courses.

The software should provide exceptional tools for managing educational graphics and text-based information. It should also provide outstanding support for the student learning process and for instructor support.

\section{CONCLUSION}

Computer-assisted instruction has the potential to be of great value to the optics/photonics industry education efforts. This paper provides a means of understanding the research basis for more complex problem-based educational programs. It also provides a means of evaluating Internet course software attributes.

\section{ACKNOWLEDGEMENTS}

The author would like to thank the members of the Astronomy Village Development team, including John Hornyak, Drs. Steven Croft, Steve McGee, Bob Myers, Jeanne Finstein, and Nitin Naik of the Center for Educational Technologies at Wheeling Jesuit University. My sincere thanks to George Chapman for his work in developing distance learning software that has many of the attributes described herein. The Astronomy Village software was developed under funding from NASA. The author acknowledges the Department of Energy which funded some of the work on which this paper is based, under an SBIR grant, Mr. George Chapman, project manager.

\section{REFERENCES}

\footnotetext{
${ }^{1}$ Lazarowitz \& Tamir, Chapter 3: "Research on Using Laboratory Instruction in Science, in Handbook of Research on Science Teaching and Learning, edited by D. L. Gabel, Macmillan, 1994.

2 J. Gorrell, Outcomes of using computer simulations. Journal of Research on Computing in Education, 24 (3), 359-380, 1992.

${ }^{3}$ F.Neelamkavil, Computer Simulation and Modelling. John Wiley \& Sons: New York, 1987.

4 S. Pompea and C. Blurton, "A Walk through the Astronomy Village", Mercury, Jan/Feb.1995

${ }^{5}$ S. Pompea, Image Processing Exercises for Astronomy, West Publishing 1994.

6 S. Pompea, Editor, Great Ideas for Teaching Astronomy, 3rd edition, Brooks Cole, 2000.

7 S. Pompea, Editor, Current Perspectives in Physics and Astronomy, West Publishing, 1995.

${ }^{8}$ S. Pompea, and M. Nofziger, "Resources on optics in middle school education", Proceedings SPIE: 1995 International Conference on Education in Optics, Edited by M. J. Soileau, vol. 2525. 1995.

9 N. S. Hong, "The Relationship between Well-structured and Ill-structured Problem Solving in Multimedia Simulation”, Ph.D. dissertation Pennsylvania State University, 1998.

${ }^{10}$ H. A. Simon, H. A., The Structured of Ill-Structured Problems, Artificial Intelligence, 4, 1973.
} 
${ }^{11}$ E. S. Anderson, H.T. DeMeio, M. Szabo, \& G. Toth,. Behavioral objectives, science process, and learning from inquiry-oriented instructional materials. Science Education, 59(2), 263-271, 1975

${ }^{12} \mathrm{~K}$. Tobin, Students task involvement and achievement in process-oriented science activities. Science Education, 70(1), 61-72, 1986).

${ }^{13}$ C. S. Cavin and J. J. Lagowski, "Effects of computer simulated or laboratory experiments and student aptitude on achievement and time in a college general chemistry laboratory course", Journal of Research in Science Teaching, 24(2), 145-160, 1978. 